\title{
Retirement intentions of general practitioners aged 45-65 years
}

\author{
Thomas D Brett, Diane E Arnold-Reed, Dana A Hince, Ian K Wood and Robert G Moorhead
}

$\mathrm{R}$ etirement rates assume critical importance as the workforce progressively ages. ${ }^{1}$ A quarter of the Australian medical workforce is aged over 55 years, ${ }^{2}$ making premature retirement a major factor in workforce supply. ${ }^{3}$ Among health professional groups, general practitioners have traditionally been one of the latest retiring, ${ }^{3}$ but recent demographic changes ${ }^{1-3}$ and shifting discourses of professionalism ${ }^{4}$ have focused attention on the ability of GP supply to meet future demand. ${ }^{1-3,5}$ A key strategy to provide sufficient GP services is to minimise early retirement by maintaining senior, experienced doctors in the workforce until usual retirement age..$^{3,5-7}$ This study examined the retirement intentions of a cohort of older Australian GPs and the reasons for these intentions.

\section{METHODS}

Questionnaires were mailed to 478 GP members of four Western Australian Divisions of General Practice; three Divisions mailed them to GPs within the target age range, and one to all their GPs. Questionnaires were sent between November 2007 and January 2008 (6 months before the 2008 global financial crisis). To ensure participant anonymity, questionnaires were coded and mailed out by Division staff, but returned by participants to researchers; replies were anonymous. Ethics approval was gained from the University of Notre Dame Human Research Ethics Committee.

The 18-item questionnaire was a modified version of a questionnaire used for a similar survey of GPs in the United Kingdom. ${ }^{8}$ Questions were asked about GPs' background (age, sex, year and country of graduation, vocational registration, Fellowship of the Royal Australian College of General Practitioners [FRACGP] or equivalent) and current work situation (practice size, sessions worked per week and whether home, nursing home or hostel visits were undertaken).

Tick-box options were provided for questions on current workload and intention to work to age 65 years. An open question was used to ascertain perceived obstacles to Australian general practice; participation in focus group discussion was made available. Prospective early retirees were asked their intended retirement age, and to provide reasons for early retirement and a list of incentives that might encourage them to continue working; they were given the opportunity to expand on the appeal of their listed incentives.

\section{ABSTRACT}

Objective: To ascertain the retirement intentions of a cohort of Australian general practitioners.

Design and setting: Postal questionnaire survey of members of four Divisions of General Practice in Western Australia, sent out November 2007 - January 2008.

Participants: A sample of 178 GPs aged $45-65$ years.

Main outcome measures: Intention to work in general practice until retirement; reasons for retiring before age 65 years; factors that might encourage working beyond chosen retirement age; and perceived obstacles to working in general practice.

Results: $63 \%$ of GPs intended to work to at least age 65 years, with men more likely to retire early. Of $63 \mathrm{GPs}$ intending to retire early, $46 \%$ gave pressure of work, exhaustion and burnout as reasons for early retirement. Better remuneration, better staffing levels and more general support were incentives to continue working for $46 \%$ of the 64 GPs who responded to the question about incentives, and more flexible working hours, part-time work and reduced workload for $41 \%$. Of 169 participants, $65 \%$ gave increasing bureaucracy, poor job satisfaction and disillusionment with the medical system or Medicare as obstacles to working in general practice in Australia, whereas workforce shortage, increasing patient demands and diminishing lifestyle through overwork were obstacles named by $48 \%$.

Conclusion: Many GPs are planning to retire early, reflecting an emerging trend among professionals and society generally. Declining job satisfaction, falling workforce numbers, excessive workload and increasing bureaucracy were recurrent concerns of older WA GPs considering premature retirement.

MJA 2009; 191: 75-77

\section{Data analysis}

Open questions were analysed as described by the UK researchers. ${ }^{8}$ Agreement between coders was measured using Krippendorff's $\alpha$ reliability measure ${ }^{9}$ (why retirement before age 65 years was being considered: $\alpha=0.38$; incentives to continue working: $\alpha=0.75$; major obstacles to working as a GP in Australia: $\alpha=0.45$ [ $\alpha$ values closer to 1.0 indicate better agreement]).

Results are presented as frequencies with 95\% confidence intervals. Odds ratios (ORs) were calculated using the binary logistic procedure in SPSS, version 15.0 (SPSS Inc, Chicago, Ill, USA). $P<0.05$ was considered significant.

\section{RESULTS}

Responses were received from 281 GPs (59\% response rate). Of these, 179 were within the 45-65 years age group, with one not practising, leaving a study population of 178 GPs. Focus group discussions were not undertaken, as $71 \%$ of respondents said they did not want to participate.

Box 1 shows study population demographics. Mean and median ages of the cohort were $52.4(\mathrm{SD}=5.2)$ and 51 (inter-quartile range,
48-56) years, respectively. Sixty-nine per cent (95\% CI, 61\%-77\%) of men worked eight or more sessions compared with $31 \%$ (95\% CI, $19 \%-46 \%)$ of women $\left(\chi^{2}=21.5 ; P<0.001\right)$. Forty-seven per cent $(95 \% \mathrm{CI}, 40 \%-55 \%)$ and $49 \%$ (95\% CI, $41 \%-56 \%)$ of GPs reported their workload to be too heavy and about right, respectively.

Sixty-three per cent (95\% CI, 56\%-71\%) stated they intended to work in general practice at least until age 65 years and $6 \%(95 \% \mathrm{CI}$, $3 \%-11 \%$ ) were unsure when they would retire. Seventy-five per cent (95\% CI, 60\%$86 \%$ ) of women GPs compared with 59\% (95\% CI, 50\%-68\%) of men GPs said they would work to normal retirement age. There was a trend for men to be less likely to intend to work until at least 65 years than women $(\mathrm{OR}=0.49 ; 95 \% \mathrm{CI}, 0.23 \%-1.02 \% ; P=0.06)$.

Percentage frequencies of reasons for retiring before age 65 years are shown in Box 2, A. The most commonly cited reasons were pressure of work, exhaustion and burnout (46\%). Box 2, B shows the percentage frequencies of factors that might encourage working beyond chosen retirement age. The most enticing incentives for $46 \%$ of respondents were better 


\section{Demographics of 178 Western Australian general practitioners}

\begin{tabular}{lc} 
& Number (\%) \\
\hline Sex & $130(73 \%)$ \\
Men & $48(27 \%)$ \\
Women & \\
Age group (years) & $78(44 \%)$ \\
$45-50$ & $49(28 \%)$ \\
$51-55$ & $35(20 \%)$ \\
$56-60$ & $16(9 \%)$ \\
$61-65$ & \\
Country of graduation & $109(61 \%)$ \\
Australia & $69(39 \%)$ \\
Overseas & \\
Number of doctors in & \\
practice & \\
1 & $13(7 \%)$ \\
$2-4$ & $66(37 \%)$ \\
$\geqslant 5$ & $99(56 \%)$ \\
Sessions worked per week & \\
$<5$ & $22(12 \%)$ \\
$5-8$ & $50(28 \%)$ \\
$>8$ & $105(59 \%)$ \\
Unknown & $114(1 \%)$ \\
Home visits & \\
Nursing home or hostel \\
Visits
\end{tabular}

FRACGP $=$ Fellow of the Royal Australian College of General Practitioners.

remuneration, better staffing levels and more general support; $41 \%$ selected more flexible working hours, part-time work and reduced workload. Box 3 shows the percentage frequencies of what GPs considered obstacles to working in general practice. For 65\%, increasing bureaucracy, poor job satisfaction and disillusionment with the medical system or Medicare were the most notable obstacles; $48 \%$ selected workforce shortage, increasing patient demands and diminishing lifestyle through overwork.

\section{DISCUSSION}

Australian GPs are starting to plan early retirement, reflecting an emerging trend among professionals and society generally. ${ }^{4,5,10-12}$ of the 178 GPs surveyed, a third planned to retire before age 65 years, consistent with results of earlier research. ${ }^{1,7,12}$ Unlike the overall Australian population where women generally

\section{Responses to questions about retirement of participants who said they would not, or did not know if they would, work to the age of 65 years*}

A. Please explain briefly why you are considering leaving before usual retirement age $(n=63)$

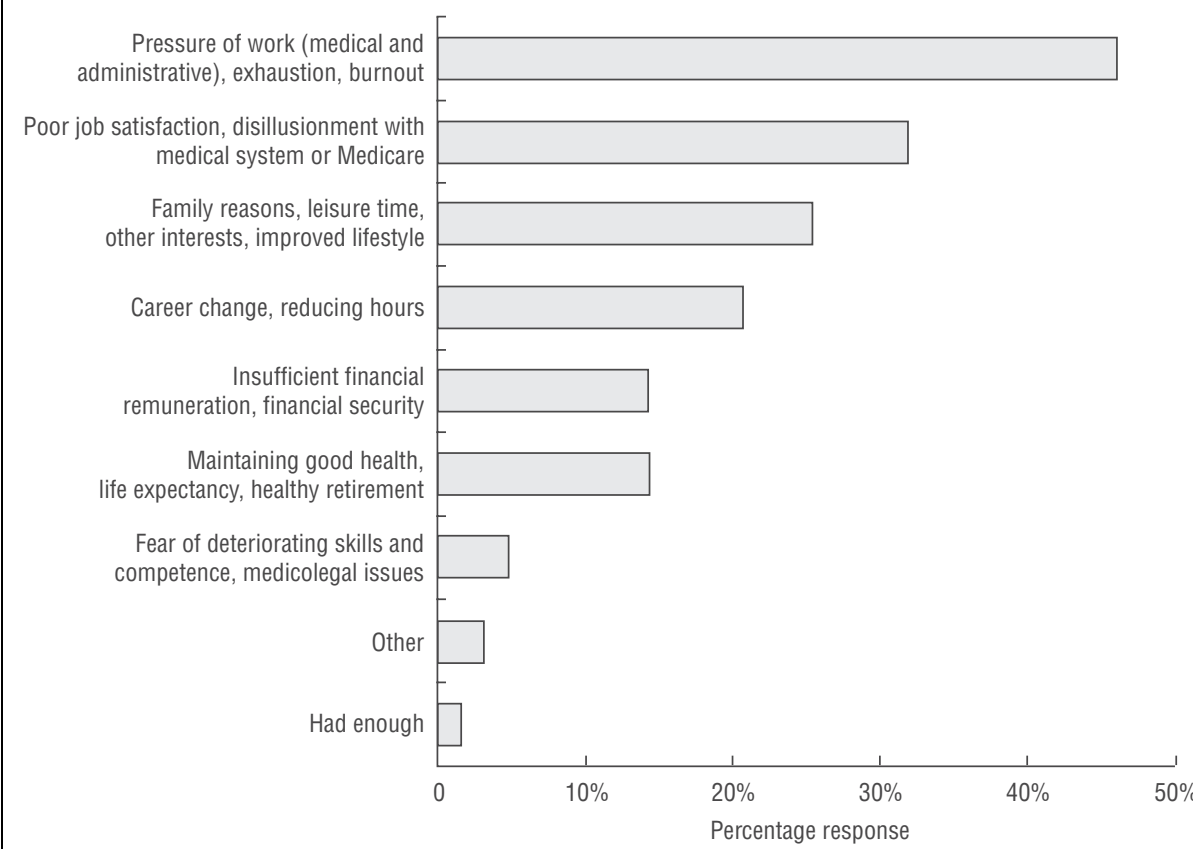

B. What might encourage you to stay working until usual retirement age? $(n=61)$

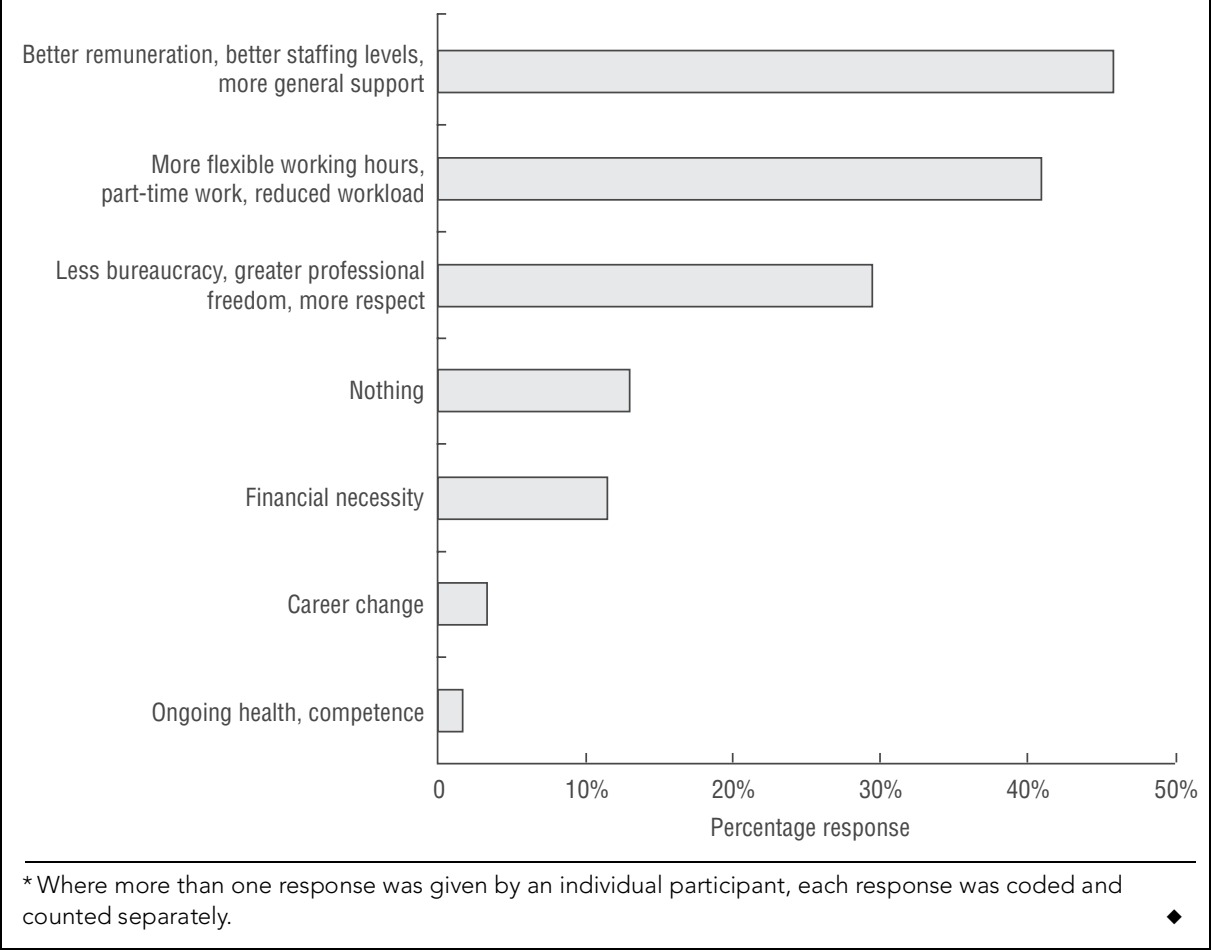

retire earlier than men, ${ }^{13}$ women GPs reported they were more likely to want to continue working to a later age than men. This is consistent with earlier UK research ${ }^{14}$ and may reflect, as noted by other authors, ${ }^{7}$ that women generally were more satisfied with their work than men - possibly because they were more likely to be working part-time. This result contrasts with the findings of an analysis of Australian Bureau of Statistics census data for 1986, 1991, 1996 and 2001 ${ }^{3}$ and may indicate shifting demographics and the desire to achieve greater "work-life balance" 4 in the Australian GP workforce in more recent years. 


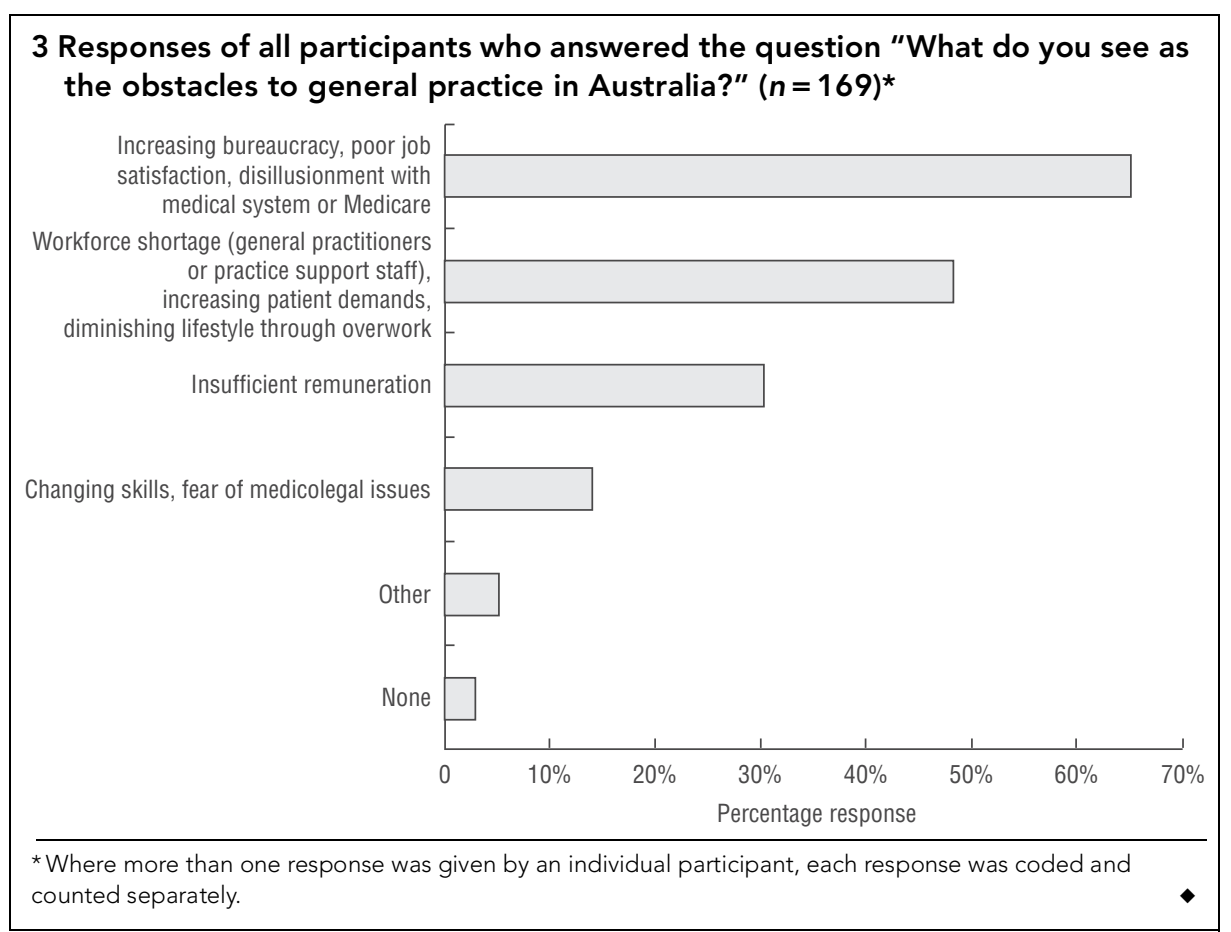

Consistent with overseas findings, $4,6,7,12,15$ diminishing job satisfaction, increasing bureaucracy, falling workforce numbers, excessive workload and a desire for more leisure time were recurrent themes throughout this study. Lack of job satisfaction links the other factors that motivate GPs to retire early. Authors of a UK study ${ }^{7}$ identified this factor as being amenable to intervention and pointed out that increasing the retention rate of GPs was a more cost-effective and immediate option than training new doctors.

As previously reported, ${ }^{7,12,15}$ the everchanging governance of general practice brings discontent and contributes to "unhappy" doctors. ${ }^{16}$ Changes include the introduction of accreditation, care plans and health assessments, and increased bureaucracy. $^{17}$ Older GPs find change difficult, and declining morale occurs partly because current medical practice is considerably different to that for which they were trained. ${ }^{7}$

What policy changes might encourage senior GPs to continue working? This study, as with previous research, ${ }^{7,12,16}$ shows a relationship between job satisfaction and remaining in the workforce. Measures such as encouraging men GPs to gradually reduce workloads, eliminating unnecessary bureaucratic demands, and improving financial rewards might increase job satisfaction.

A shortage of doctors in general practice will have repercussions at all levels of the health system. It will inevitably impede hospital efficiency ${ }^{1}$ and slow discharge of patients back to their communities. The continued involvement of experienced GPs in health care is critical, ${ }^{18}$ yet the opportunity to engage them may not last for long.

\section{ACKNOWLEDGEMENTS}

We acknowledge the administrative support provided for this project by Ms Philomena de Lima and staff of the four participating Divisions of General Practice: Fremantle General Practice Network, General Practice Down South, Greater Bunbury and Rockingham-Kwinana. Ian Wood was supported by the Researcher Development Program Fellowships or Clinical Bursaries offered under the Commonwealth Primary Health Care Research Evaluation and Development (PHCRED) Strategy Phase II. Thomas Brett, Diane Arnold-Reed, Dana Hince and Robert Moorhead were funded by PHCRED.

\section{COMPETING INTERESTS}

None identified.

\section{AUTHOR DETAILS}

Thomas D Brett, MD, MRCGP, FRACGP, Associate Professor and Director

Diane E Arnold-Reed, BSc(Hons), PhD, Associate Professor

Dana A Hince, BSc(Hons), PhD, Statistical

Ian K Wood, MBBS, FRACGP, General

Practitioner and Researcher Development Program Fellow

Robert G Moorhead, MD, FRACGP, MICGP, General Practitioner and Research Advisor

General Practice and Primary Health Care Research, School of Medicine, University of Notre Dame, Fremantle, WA.

Correspondence: tbrett@nd.edu.au
Support Officer

\section{REFERENCES}

1 Joyce CM, McNeil JJ, Stoelwinder JU. More doctors, but not enough: Australian medical workforce supply 2001-2012. Med J Aust 2006; 184: 441-446.

2 Australian Institute of Health and Welfare. Medical labour force 2005. Canberra: AlHW, 2008. http:// www.aihw.gov.au/publications/index.cfm/title/ 10548 (accessed Aug 2008).

3 Schofield DJ, Beard JR. Baby boomer doctors and nurses: demographic change and transition to retirement. Med J Aust 2005; 183: 80-83.

4 Jones L, Green J. Shifting discourses of professionalism: a case study of general practitioners in the United Kingdom. Sociol Health IIIn 2006; 28: 927-950.

5 Charles J, Britt H, Valenti L. The evolution of the general practice workforce in Australia, 1991 2003. Med J Aust 2004; 181: 85-90.

6 Health Policy and Economic Research Unit. Work related stress among senior doctors. London: British Medical Association, 2000.

7 Sibbald B, Enzer I, Cooper C, et al. General practitioner job satisfaction in 1989, 1990 and 1999: lessons for the future. Fam Pract 2000; 17 : 364-371.

8 Davidson JM, Lambert TW, Parkhouse J, et al. Retirement intentions of doctors who qualified in the United Kingdom in 1974: postal questionnaire survey. J Public Health Med 2001; 23: 323-328.

9 Hayes AF, Krippendorff K. Answering the call for a standard reliability measure for coding data. Commun Methods Meas 2007; 1: 77-89.

10 Jacobs K, Kohli M, Rein M. The evolution of early exit: a comparative analysis of labour force participation patterns. In: Kohli M, Rein M, Gullemard A, van Gunsteren $H$, editors. Time for retirement: comparative studies of early exit from the labour force. Cambridge: Cambridge University Press, 1991: 36-66.

11 Mein G, Martikaine P, Starsfield S, et al. Predictors of early retirement in British civil servants. Age Ageing 2000; 29: 529-536.

12 Sibbald B, Bojke C, Gravelle H. National survey of job satisfaction and retirement intentions among general practitioners in England. BMJ 2003; 326: 1-7.

13 Australian Bureau of Statistics. Retirement and retirement intentions, Australia, Jul 2006 to Jun 2007. Canberra: ABS, 2008. (ABS Cat. No. 6238.0.) http://www.abs.gov.au/AUSSTATS/abs@.nsf/ DetailsPage/6238.0Jul\%202006\%20to\%20 Jun\%202007? OpenDocument (accessed Mar 2009).

14 Taylor K, Lambert T, Goldacre, M. Future career plans of a cohort of senior doctors working in the National Health Service. J R Soc Med 2008; 101: 182-191.

15 Luce A, van Zwanenberg T, Firth-Cozens J, et al. What might encourage later retirement among general practitioners? J Manag Med 2002; 16: 303-310.

16 Edwards N, Kornaki M, Silverstein J. Unhappy doctors: what are the causes and what can be done? BMJ 2002; 324: 835-838.

17 Australian Medical Workforce Advisory Committee Report. The general practice workforce in Australia: supply requirements to 2013. Sydney: AMWAC, 2005.

18 Schofield DJ, Page SL, Lyle DM, et al. Ageing of the baby boomer generation: how demographic change will impact on city and rural GP and nursing workforce. Rural Remote Health 2006; 6: 604.

(Received 10 Oct 2008, accepted 30 Jan 2009) 